\title{
[ 2819$]$
}

VI.

Auszug aus einem Schreiben des Profeffors

Lü dicke. Meifsen, 12 Febr. 1810.

- $\mathrm{D}_{\text {ie }}$ Farbenverfuche und die Berech. nungen derfelben, welche Sie hier als Fortfetzung meiner Unterfuchungen über die Mifchung der prismatifchen Farben erhalten, haben mir fo vie] Arbeit gemacht, dafs ich die darauf gewendete Zeit bedauern würde, wenn ich nicht hoffen dürf. te, etwas Nutzbares geliefert zu haben. Die erfte Ab̆theilung, über die Entftehung des prismatifchen Farbenbildes, welche den Beweis liefert: dafs zwei gebeugte Hauptftrahlen das Bild hervor bringen, wird Ihnen nicht minder als mir, fehr nützlich zur Verbefferung der Farbentheorie fcheinen. Die Newton'fche verfchiedene Brechbarkeit des Lichts überhaupt mufs nunmehr blofs von dem gebeugten Lichte gelten. Jedoch ich fetze ohnehin diefen Gegenftand ncch fort, und habe nun fchon ein Chromafkop, eine Art von Camera obfcura, welche ein grofses Prisma von Flintglas entbält, verfertigt, um diefen Gegenftand noch näher zu beftjmmen; habe auch das Inftrument fo eingerichtet, dafs es, 10 viel als möglich, ein Chromameter feyn kann. Doch ich will nichts mit Zuverläffigkeit verfprechen, weil ich meiner hinfäligen Gefundheit nicht viel zutraue. In Heft 1 . diefes Jahrs fehlt S. 2. Z. 6. das Wort beftätigt. S. 3. Z. 4. lies zearen ftatt war, und S. 14. Z. 4. kamen ftatt kam. 